\title{
Perceiving words during reading: Lack of facilitation from prior peripheral exposure
}

\author{
GEORGE W. MCCONKIE, DAVID ZOLA, HARRY E. BLANCHARD, \\ and GARY S. WOLVERTON \\ University of Illinois at Urbana-Champaign, Champaign, Illinois
}

\begin{abstract}
As their eye movements were being monitored, college students read short texts displayed on a cathode-ray tube. As they read, the contents of certain word locations changed from fixation to fixation, alternating between two words differing in two letters. This manipulation had no effect on reading unless the subjects happened to regress to or reread the word later. The results indicated that these words, which were low in contextual constraint, were read only when directly fixated, and that there was no facilitation from prior peripherally obtained information about the words.
\end{abstract}

Present evidence suggests that visual information acquired from peripheral visual areas on one fixation during reading facilitates the identification of words available foveally on the next fixation (McConkie \& Rayner, 1976a; Rayner, 1975, 1978). While there are many possible mechanisms by which such facilitation might be achieved, for present purposes these can be divided into two broad categories. First, it may be that words are often perceived in subword units (letters, letter groups, syllables, etc.), with one or more subunits of a word being perceived on one fixation and the remainder on the next (McConkie, 1979). Thus, words may be identified from subparts which are frequently obtained on different fixations. This position will be referred to as the subword-unit hypothesis. It would suggest that parts of a word perceived on one fixation are not reprocessed on the next, and that the individual fixation span (Underwood \& McConkie, Note 1), or the region perceived during a fixation, does not necessarily extend to word boundaries.

A second way in which peripherally obtained information might facilitate processing of the foveal stimulus on the next fixation will be referred to as the information-accrual hypothesis. This assumes that the stimulus pattern, while lying too far into the periphery to support word identification, has still been partially processed, and the information gained facilitates word or meaning identification on the next fixation. For instance, it may be that certain features of a word, such as its general shape or length, or features of some letters in the word, have been ob-

This research was conducted under Grants MH 32884 and MH 33408 from the National Institute of Mental Health to the first author and National Institute of Education Contract HEWNIE-C-400-76-0116 to the Center for the Study of Reading. Copies of this paper can be obtained by writing to George W. McConkie, Center for the Study of Reading, 51 Gerty Drive, Champaign, Illinois 61820 . tained, or that some sort of preprocessing has permitted priming of the lexical entries of a word set which includes the correct word, on the basis of semantic or phonological information, for instance. In general, this hypothesis assumes that the information obtained is not the identification of subparts of the word (letters or orthographic units), but is more general information that places constraints on what the word might be. Admittedly, the distinction between these two hypotheses becomes difficult if one thinks of features of words or letters as being subparts of those units, but this will not cause difficulty in the context of the present study.

The other possibility, of course, is that information obtained peripherally from a word on one fixation does not facilitate its processing when it comes into the foveal region for the next fixation. This could occur either because such visual analysis of peripheral words is not attempted during fixations in reading or because, when identification of a word fails, all information accumulated about it is discarded and processing begins anew on the next fixation. This would require that words typically be identified only from the visual pattern present during a fixation, without the use of information obtained during prior fixations. There would certainly have to be exceptions to this, as when words are split between two lines or two pages, or when a word is so long as to require more than one fixation to perceive it. These conditions would necessitate the additional ability to perceive and use subparts, such as syllables or the parts of compound words. However, it would assume that this was not normally the way perception proceeds in skilled reading. This position will be referred to as the word-unit hypothesis, since it assumes that entire words are typically identified durin a single fixation, rather than being perceived in subparts or accruing information about them to be used later. 
Present evidence favors the peripheral acquisition of information, and thus stands against the wordunit hypothesis, although it is unclear whether this facilitation occurs in an information-accrual or subword-unit manner. Having erroneous letters in the periphery during one fixation can inflate the duration of the next fixation, when that region is brought into foveal vision, even though the errors have now been replaced by normal text (O'Regan, 1980; Rayner, 1975; Underwood \& McConkie, Note 1). In addition, as Rayner (1975) found, if a word is changed. during the saccade taking the eyes to that location, some disruption results, even when both words are appropriate to the context. Similarly, in a wordnaming task, having a word in the periphery during one fixation reduces the time required to name it when it is in the fovea on the next fixation (Rayner, 1978; Rayner, McConkie, \& Ehrlich, 1978), although this facilitation may depend on subjects' familiarity with the word set used or on the degree of contextual constraint operating (McClelland \& O'Regan, 1981; Paap \& Newsome, 1981). These results have been taken as support for the notion that information obtained peripherally on one fixation is brought to bear in perceiving those words on the next fixation. The information carried across is apparently not strictly visual in nature (McConkie \& Zola, 1979), and there is some evidence that it may not be semantic or phonetic (Rayner, McConkie, \& Zola, 1980). However, these studies have failed to indicate whether the information obtained peripherally was of subword units (McConkie, 1979) or more general information accrual. One study suggests that it may be subword units that are acquired, although the task used was one of naming words rather than one of normal reading (Rayner, McConkie, \& Zola, 1980).

The present study attempted to investigate, in a more controlled manner, whether peripheral facilitation was taking place during reading, and, more importantly, to do this in a way which would allow a choice between the subword-unit hypothesis and the information-accrual hypothesis as an explanation for any observed facilitation. In order to do this, sets of four words which differed in only two letters (for example, pears, bears, peaks, and beaks) were identified. Sentences which contained one word location in which any of the four words could appropriately fit were then written. Subjects read these sentences, displayed on a cathode-ray tube (CRT) under computer control, as their eye movements were being monitored. During saccades in the region around the critical word location, the display was changed from one of two of the words that differed in both letters (e.g., bears and peaks) to the other. Thus, the word in that location alternated between two of the possible words on successive fixations. If the subword-unit hypothesis is an accurate de- scription of perception during reading, there should be times when subjects would acquire the first letter of the word during one fixation and the fourth letter during the next, thus perceiving a word which was, in fact, never present on the CRT (beaks or pears in the above example). This could well occur without any evidence of disruption in the eyemovement pattern, since the reader would likely not know the word had changed. Any combination of letters perceived as the word changed would result in an appropriate reading of the sentence. On the other hand, if perception occurs by an information-accrual process, then the change of the pattern in that word position from one fixation to the next should produce disruption in reading, as found in prior studies, but it would be unlikely that the reader would report seeing words that were never actually on the CRT. Finally, if subjects showed no evidence of disruption from the changing letters, and also failed to perceive words not present on the CRT (but constructed from parts of words that were present), this would be taken as evidence for the word-unit hypothesis.

\section{METHOD}

\section{Subjects}

The subjects were 16 University of Illinois undergraduates who had normal uncorrected vision, were native speakers of English, and were paid for their participation in the experiment. All the subjects had previously participated for 4 to $6 \mathrm{~h}$ in another experiment involving the same general type of task.

\section{Materials}

Twenty-five quadruplets of five-letter words were chosen such that each word in a set differed from one of the other words in only the first letter, from a second word in only the fourth, and from the remaining word in both the first and fourth letters. For each quadruplet, a short text of one to three sentences was constructed which made sense when any of the four words occupied a particular word position, to be referred to as the critical word location. These texts are presented in the Appendix. In addition to these texts, eight others of similar length and style were used as warm-up and filler sentences.

\section{Apparatus}

The text was displayed one line at a time on a Digital Equipment Corporation Model VT-11 CRT. The CRT has a P-31 phosphor that decays to $1 \%$ of the original intensity in $500 \mu \mathrm{sec}$ and a hardware character generator capable of producing upperand lowercase letters. The display was refreshed every $3 \mathrm{msec}$. Thus, display changes could be made within $3 \mathrm{msec}$ without interrupting the refresh cycle. The CRT was $68 \mathrm{~cm}$ away from the subject, which made $1 \mathrm{deg}$ of visual angle equivalent to four character positions. The subject was provided with a button which called the next line of text onto the CRT.

Eye movements were monitored with an SRI Dual Purkinje Eyetracker. The procedures currently used maintain an accuracy within $1 / 4$ deg of visual angle. Only the horizontal channel of the eyetracker was monitored. The CRT and the eyetracker were interfaced with a Digital Equipment Corporation PDP-11/40 computer, which was programmed to sample eye position every millisecond and to make display changes at certain times when the eyes were identified as being in a saccade. 


\section{Procedure}

The subjects were fitted with a bite bar and headrest in order to minimize head movement. The 33 texts were split into two groups with a short rest in between. Before and after reading each group, the subjects were engaged in a calibration task, in which they successively fixated on five dots placed at equidistant points on the CRT on the line on which text was to be displayed. As each dot was fixated, the subject pressed a button, which caused the computer to sample the voltage level of the eyetracker for that position. These values were used to translate eyetracker voltage levels to eye-position locations on the CRT while the subject was reading. Values obtained before and after reading each group of texts were compared to judge the accuracy of the data.

While the subjects read each text, display changes occurred during saccades made in the region of the critical word. The display change consisted of substituting one line of text for another while the eyes were in a saccade. In the experimental condition, the substituted line of text was the same as the original except that the first and fourth letters of the critical word had been changed, replacing the word with its alternative. So, for successive fixations in the vicinity of the critical word, two words differing in two letters alternated from one fixation to another. For example, if on one fixation the word blame were present, on the second, it would be flare, on the third, blame, on the fourth flare, etc. (with the actual switching occurring during the saccades between the fixations). In the control condition, the substituted line of text was identical to the original line, so that on each fixation the same alternative was present.

The region within which this switching occurred was defined in the following manner. Three boundaries were set on each line containing a critical word location. The first, the enabling boundary, was always 11 character positions to the right of the beginning of the line. No display changes were permitted until the eyes had fixated at least once to the left of that boundary. The second, the initiating boundary, was 18 character positions to the left of the critical word location, or one position to the right of the enabling boundary if it was 18 or fewer character positions to the left of the critical word location. The first display change occurred during the saccade following the first fixation to the right of the initiating boundary, given that the eyes had previously fixated left of the enabling boundary, and the word changed during each following saccade until terminated by one of two possible events. The third boundary, the terminating boundary, was 11 character positions to the right of the first letter of the critical word location. Display changes were permanently disabled for a given line following the first fixation to the right of the terminating boundary, or following the first regressive saccade, after such changes had been initiated. Thus, display changes occurred only during saccades following fixations that lay between the initiating and terminating boundaries. Within this region, they occurred only if (1) the enabling boundary had previously been crossed, (2) no previous regressions had been made since the region was entered, and (3) this region had not been read previously (that is, the initiating and terminating boundaries had not previously been crossed, in that order). With this algorithm, the decision as to whether a display change should occur during a saccade was made during the prior fixation, making it possible to insure that all changes took place early during the saccade and that none occurred at or after the time the eyes were coming into a fixation.

After reading each text, the subject was presented with each of the words in the quadruplet relevant to that text, one at a time. The order of these test words was randomized for each text. The subject was instructed to indicate whether each test word had been present in the text. The subject was supplied with two buttons, one to indicate "yes" and one to indicate "no." Note that in each test set for texts in the experimental condition, two words had actually been in the text and the other two had not. In the control condition, only one of the four words had been present during reading.
Each subject received the texts and test items in the same order, but the order of assignment of conditions to texts was counterbalanced across subjects. The subjects were divided into eight groups. Groups 1 to 4 had 13 experimental and 12 control texts. For Groups 5 to 8 , the conditions to which the texts were assigned were reversed, resulting in 12 experimental and 13 control texts. Groups 1 to 4 each had a different word in the critical word location when the text initially appeared, as did Groups 5 to 8. The initially appearing word was the only word present in the control texts; in the experimental texts, the contents of the critical word location alternated between the initially appearing word and the word created by changing both the first and fourth letters. Thus, the conditions, texts, and word alternatives were all counterbalanced with respect to each other.

\section{RESULTS}

The results will be reported as providing answers to four questions. First, how accurate were the subjects' responses on the test items? Second, did the subjects report seeing words that were never present as they read under the experimental conditions? Third, within what region were the critical letters perceived? Fourth, did the letter changes that were taking place cause interference (or reduce normal facilitation) during reading?

\section{Accuracy of the Subjects' Responses}

The different patterns of responses to the test items and the frequency with which each occurred are shown in Table 1. An examination of the response patterns for the texts read under the control condition, in which the same word always occupied the critical word location, indicates that $85 \%$ of the time the subjects reported seeing only the word actually present in the text. On another $5.5 \%$ of the instances, they chose the correct word plus another word; on $3.5 \%$, they selected no word; and on the remaining $6 \%$, they chose a wrong word, one not in the sentence.

Table 1

Responses Given to Test Word

\begin{tabular}{|c|c|c|}
\hline \multirow{3}{*}{ Response Type } & \multicolumn{2}{|c|}{ Frequency } \\
\hline & $\mathrm{C}$ & E \\
\hline & \multicolumn{2}{|c|}{ Correct Response } \\
\hline Total & 170 & 161 \\
\hline Single Correct Response & 170 & 156 \\
\hline Two Correct Responses & $*$ & \\
\hline
\end{tabular}

Two Correct Responses

Errors

Total

No Response

7

Single Erroneous Response

12

Multiple Words, Including Correct Response

Multiple Words, Not Including Correct Response

$11 \quad 13$

Overall

Total

200 200

Note $-C=$ control texts; $E=$ experimental texts.

* Not applicable because there was only one correct response. 
Of the 23 instances in which an erroneous word was selected, in 22 the selected word shared one letter with the original. Only once did a subject choose a word differing in both letters. Thus, even when a wrong word was reported, it tended to maintain information from the original word. In the 12 instances in which a single erroneous word was selected, it shared the first letter with the original word four times, the fourth letter seven times, and neither letter only once. Thus, there was no tendency for the first letter to be maintained more frequently than the fourth, as might have been expected. Finally, it should be noted that in every case in which an error was made (including selecting none of the test words), the subjects' eyes had been centered on the critical word on at least one fixation. The errors did not arise from physically skipping over the word.

In general, then, subjects were quite accurate in selecting the word that was in the text in the control condition, although some errors were made.

\section{Frequency of Selecting Nonpresented Words in the Experimental Condition}

Table 1 gives the frequencies with which subjects reported having seen words that were never present on the CRT as they read. While this occurred more frequently under the experimental condition than under the control, this difference was small (31 vs. 23) and not statistically significant. Thus, it appears that these five-letter words were seldom, if ever, being perceived from subunits acquired on two successive fixations. In the experimental condition, as in the control, most of the time the subjects reported having seen one of the words that was present in the text as they read.

\section{The Region Within Which the Letters Were Being Identified}

In order to obtain a general indication of the region within which the eyes were centered when the critical word was being read, experimental condition instances were selected in which the subject (1) made a single correct response and (2) showed no regressions and no refixations following a regression in the region around the critical word (from 10 letter positions prior to it to 5 letter positions following it) and in which (3) the letter was switching during saccades and (4) the equipment was tracking the reader's eyes properly. This yielded a total of 73 unambiguous cases. All fixations on these sentences between 15 letter positions to the left of the critical word and 6 to the right were then classified according to (1) their location with respect to the critical word and (2) whether or not the word present during that fixation was the one reported as having been seen. These data are plotted in Figure 1. The circles indicate the total number of fixations centered at each letter position. There is a maximum at the lo-

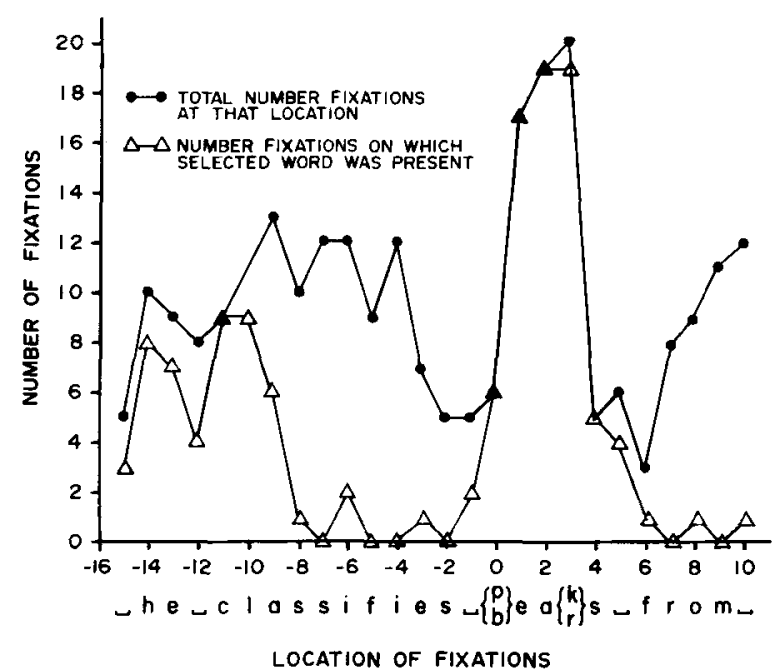

Figure 1. Number of fixations at each letter position with respect to the critical word location, and the number of these on which the word selected as having been seen was present during that fixation. Only data from instances in which the subject did not regress into this region, and in which the subject responded correctly on the test, are included.

cation of the critical word with minima to either side, reflecting the tendency of subjects to fixate the centers of words (O'Regan, 1981; Rayner, 1979a; Zola, Note 2). This maximum does not necessarily reflect any tendency to fixate the critical word more than other words; it simply reflects the fact that the data are grouped with respect to the position of that word. No such consistent correspondence exists for other words across the passages when the data are grouped in this manner.

The data of interest are the frequencies with which the word present during fixations at different locations was the word reported as being seen. Each such fixation is a candidate for being the fixation on which the word was identified (though, of course, this does not mean that the word was identified on all these fixations). The frequencies of these fixations are shown by triangles in Figure 1. As can be seen, in every instance but one in which a fixation fell directly on the critical word, the word present on that fixation was reported as having been seen. of 11 fixations on the space prior to and following the word, the word reported as being seen was present on 6. And during fixations on the five locations before or after the word (including spaces before and after), the word reported was present on only 5 of the 88 fixations. In each of these latter cases, there was another fixation directly on the critical word or on the space before or after, on which the reported word was present. Thus, it appears that the critical word was being identified only on fixations directly on that word, or sometimes on the space before or after. Apparently, whether the first or fourth letter of the critical word location 
was being employed in word perception during a fixation depended less on the location of that letter with respect to the fixation location (that is, on how many letter positions it lay to left or right of the center of vision), and more on whether the word containing it was directly fixated. The data include instances in which the fixation was centered on the fifth letter of the word, and even on the space following it, thus placing the first letter of the word four or five letter positions to the left of the fixation point, on the fixation on which the word was identified. That initial letter of the word could not have been acquired on the prior fixation, because a different letter had occupied the location on that fixation. Likewise, there are other instances in which the eyes were fixated just one or two letter positions to the left of the initial letter of the word, and that letter was apparently not picked up, in spite of prior evidence suggesting that the perceptual span tends to be asymmetric to the right (McConkie \& Rayner, 1976b; Rayner, Well, \& Pollatsek, 1980; Underwood \& McConkie, Note 1).

It appears, then, that when these readers were making a rightward series of saccades along a line of text, the region influencing word perception during a fixation was defined in terms of word units, rather than in terms of a certain number of letters to right and left of the fixation point. If a word was fixated only once (as was typically the case in these data), that fixation was typically the one that provided the visual information for the perception of that word.

The data from those instances on which a subject regressed to the critical word or reread the region containing the critical word after having regressed to an earlier region were also examined. In these instances, during most of the fixations on the word, the word reported as having been seen was present. This was typically because of the letterswitching algorithm used. When a subject regressed, the word was changed, but further changing was discontinued. Thus, if the subject made a fixation on the word, went one fixation beyond, and then returned to the word for several fixations, the word present on the fixation following the regression and all further fixations would be the same as the word that was present on the initial fixation. In spite of this aspect of the study, there were 53 instances in the experimental condition in which subjects had fixations centered directly on the critical word or on the space before or after, during which each of the two words was present. An examination of the responses made following these sentences indicated that a single correct response was given 36 times, or $68 \%$. Both words were reported three times, a correct plus one or two incorrect words six times, only an incorrect word three times, and no response six times. Thus, most of the time when a word was refixated after it had been changed, only one of the words was reported as having been seen, and the frequency of reporting both was less than that of reporting a correct word and an erroneous one. While further research is needed to investigate the possibility that subjects were not always reporting all the words they actually saw, it appears possible that, when regressions or rereadings are involved, it is not necessarily the case that a word is being identified each time it is fixated. Such a finding would raise questions about the function of such fixations, but the present data provide no additional information on this issue.

\section{Effect of Changing Letters on Reading}

Several aspects of the data indicated that changing letters from one fixation to another was producing an effect on reading. The total number of fixations on the critical word was 387 in the experimental condition and 314 in the control. The mean duration of fixations falling in the region from five letters prior to, to five letters following, the critical word was $266 \mathrm{msec}$, compared with $254 \mathrm{msec}$ for the control condition.

In order to provide unambiguous evidence concerning the effect of changing letters, the data were searched for those instances on which the first fixation on the critical word was preceded by a saccade during which the letters in the critical word were changed. Data from the control condition were selected in an identical manner, since the same algorithm had been used in controlling the display in that condition. This produced a data set of 157 instances in the experimental condition and 151 in the control condition. The first fixation on the word was labeled fixation F0, the saccade following it, saccade S1, and the next fixation, fixation F1. For each subject, the mean F0 and F1 fixation durations and the mean S1 saccade length were calculated for those experimental and control sentences which met the above criteria. Means for the experimental and control conditions were then calculated by averaging the subject means. These were compared by $t$ test for correlated means. The results are presented in Table 2 and indicate that no detectable effect was observed on either fixation F0 or saccade S1, but that a marginal effect may have been present on fixation F1. Further analysis indicated that this latter effect disappeared after all F1 fixations that followed regressive S1 saccades, or those that were centered on the critical word location (these being the second fixation on the word, and typically being preceded by a regression), were removed. Finally, as Table 2 shows, when the F1 fixations were subdivided into those that fell to the right of the critical word and those that fell on or to the left of it, a significant effect was found only for the latter. It appears, then, that the F1 fixation durations only 
Table 2

Eye-Movement Data Following Display Change Prior to Fixation Fo

\begin{tabular}{lcccccc} 
& \multicolumn{2}{c}{ Condition } & & & \\
\multicolumn{1}{c}{ Data } & Experimental & Control & t & df & p \\
\hline Number of Instances & 157 & 151 & & & \\
F0 fixation duration & 283 & 273 & .79 & & \\
S1 forward saccade length & 7.16 & 6.96 & 1.07 & & \\
Number of regressive S1 saccades & 26 & 20 & & & \\
F1 fixation duration & 275 & 254 & 1.43 & 15 & $<.09$ \\
F1 fixation duration when not on critical word & 267 & 264 & $<1$ & & \\
F1 fixation duration when S1 is not regressive & 261 & $\mathbf{2 6 1}$ & $<1$ & & \\
F1 fixation duration when F1 is right of the word & 268 & $\mathbf{2 7 4}$ & $<1$ & 15 & $<.00$ \\
F1 fixation duration when F1 is left of or on word & 281 & $\mathbf{2 1 4}$ & 2.88 & 15 & \\
\hline
\end{tabular}

Note-Fixation durations are given in milliseconds. Saccade lengths are given in number of character positions; 4 character positions $=$ 1 deg of visual angle.

showed an effect when regressions and/or refixations of the critical word were involved. It should be noted that these were cases in which the word changed again during saccade $S 1$, so the word was different on fixation F1 from what it had been on F0. It seems quite likely that this effect on fixation F1 was actually due to this second change rather than the first. Thus, there is no evidence that having a different word present during the fixation prior to that on which the word was directly fixated had any effect on processing that word. It appears that the change in the word has an influence only in some instances when a second fixation is made on the word or when there is a regression on the following saccade.

Finally, it seemed possible that the display change influenced reading only when the fixation prior to the fixation on the critical word location was close enough to it for visual detail to be resolved. To test this, the data were split into those instances in which the fixation prior to fixation F0 was fewer than five character positions to the left of the critical word location and those in which it was five or more character positions to the left. Mean FO fixation durations for experimental and control conditions in the first of these cases were 287 and $276 \mathrm{msec}$; in the second case, they were 278 and $264 \mathrm{msec}$. Neither of these differences was significant $(t<1$ and $t=1.39, p=.09$, successively), and there was no evidence for the predicted interaction.

As reported earlier, in the total data set there were more fixations in the region of the critical word in the experimental condition than in the control (from five character positions before to five after the word), and these fixations show slightly longer durations in the experimental condition. Once again, when these data are partitioned into first-pass fixations (those taking the eyes further along the line than they had previously been) and those involving regressions and rereadings, the difference is found only in the latter set. Mean fixation durations for first-pass data are 258 vs. $257 \mathrm{msec}$ for experimental and control conditions, respectively; corresponding values for the other set are 283 and $245 \mathrm{msec}$.

It seems evident, then, that the effects of changing words occurred only when the subjects regressed or reread the text. The remaining question is whether the display changes themselves induced these regressions and rereadings. Table 2 indicates that in the data which were selected on having a display change during the saccade prior to fixation F0, there was very little difference between the frequency of regressions in the experimental and control conditions on saccade S1. Furthermore, frequency distributions of the number of times that the critical word was fixated in the experimental and control conditions showed very little difference in the frequency of being fixated only once (104 vs. 111, respectively). The primary difference in these distributions was in the frequency with which the critical word received 3 or more fixations, which was 44 for the experimental condition (of which 13 instances showed 5-10 fixations) and 21 for the control (of which only 4 showed 5 or 6 fixations, none with more). Thus, it appears that the changing of the words did not induce the regressions and rereadings, but that, when a regression occurred, the fact that the word was sometimes now different tended to induce additional fixations in the experimental condition. These fixations tended to be longer in duration than fixations involved in regressions and rereading in the control condition.

It is concluded, then, that there is no evidence that the changing of the critical word from one fixation to another was having any detectable effect, either in producing longer fixations, shorter saccades, or a greater likelihood of regressing. When, for some reason other than the display change, there was a regression or the critical word was refixated, the discrepancy produced by the display change did sometimes have an effect. Thus, there is no evidence that information about the first or fourth letters of the word (or word shape involving these letters) was 
acquired from the periphery on one fixation and then influenced the processing of the critical word on the next fixation, when it was brought into foveal vision.

\section{DISCUSSION}

With respect to the hypotheses posed earlier, it seems clear that the perception of the words studied is best described by the word-unit hypothesis. There was no evidence that subword units were being acquired on successive fixations and integrated into a single perception, or that the visual information being manipulated in this study was being obtained peripherally from a word on one fixation, and then facilitating its perception on the next. Rather, the critical words were being perceived during only one fixation, that on which the word was directly fixated, and the changing of the letters had an effect only if the reader regressed or refixated the word for some reason.

These results are quite different from those obtained by Rayner (1975) and strongly challenge the notion that word perception during one fixation is facilitated by information obtained peripherally during a prior fixation (McConkie \& Rayner, 1976a; Patberg \& Yonas, 1978; Rayner, 1978, 1979b; Rayner, Inhoff, Morrison, Slowiaczek, \& Bertera, 1981; Rayner, McConkie, \& Ehrlich, 1978; Rayner, McConkie, \& Zola, 1980; Smith, 1971). If information about the critical words was being acquired on prior fixations, that information must not include letter features, even for the initial letter of the word, or even word-shape information, since word shape was changed in a number of the instances used in the study. If such information was being acquired, the present study found no evidence that it was being used to facilitate reading.

It is necessary, then, to consider why it was that the results of this study seem so contrary to prior theory and research. One possibility is that there was something peculiar about this study that inhibited the normal integrative processes during reading. This could be due either to the nature of the materials used or to the nature of the task. With regard to the materials, it should be noted that the critical word location was a relatively unconstrained word position. This was necessary in order for it to be capable of containing any of four different words, selected only on the basis of their having certain letter similarities. It may be that the acquisition and use of peripheral visual information to facilitate later word recognition occurs only when there exists a higher level of contextual constraint (Haber, 1978; McClelland \& O'Regan, 1981; Paap \& Newsome, 1981). This is a possibility that requires further investigation. On the other hand, the task could be suspect as well, especially in the present study. Subjects were asked to read short texts, consisting of one to three sentences, and then to select from among several visually similar word alternatives. It is possible that this could induce a sort of word-by-word consideration of the text that is different from the processing that takes place in more normal reading. Since all the subjects in this study had previously participated in a similar but much larger study in which they read more than $\mathbf{3 0 0}$ such texts, they may have developed a peculiar reading strategy. To test this, four naive subjects were tested in a somewhat different manner. After reading each passage, the subject came off the bite bar and answered an oral question which was designed to require more than a one-word answer and would reveal which of the words was perceived during reading. The data from these subjects were very much like those from the subjects in the main experiment. In particular, from texts read in the experimental condition there was only one instance (of a total of 44) in which a subject reported having read a word that was never presented. The control condition produced four such instances. Once again, there was no evidence for the subword-unit hypothesis, and there was no other evidence for greater confusion or difficulty in responding to the words in the experimental condition. Thus, it seems unlikely that the results were due to the task employing a test that required subjects to select from among visually similar words.

Another possible reason for the discrepant results is that earlier conclusions may have been in error. All studies involving eye-movement-contingent display control which have been taken as evidence for the existence of facilitation from prior peripheral information have involved changing the display in some manner from one fixation to the next. In most, some stimulus pattern (erroneous letters or a grating) is present in the visual periphery on one fixation, but is removed or relocated on the next fixation, so that the part of the text now in the fovea and near-fovea is veridical. When this results in a detectable change in reading (increasing reading time or causing specific changes in the eye-movement pattern), it has been assumed that this was due, at least partially, to interference from peripheral visual information or to its not providing the normal facilitation of later foveal processing (McConkie, 1979; Rayner, 1979b).

However, it should be noted that these studies actually provide three separate possible sources of difficulty for reading. The first is the existence of inappropriate stimulus patterns in the periphery during a fixation. Underwood and McConkie (Note 1) have specifically explored the effects of having erroneous letters at different retinal locations, for instance. The second is the fact that the stimulus pattern on one fixation is somehow different from what it was on the prior fixation. The third is the fact that changes are occurring on the CRT which, by themselves, can have a disrupting effect on reading. While 
it has been demonstrated that briefly replacing text with other text or letter strings during a saccade has no effect on reading, it is also true that changes occurring during the first $30 \mathrm{msec}$ of a fixation produce disruptive effects on reading (Wolverton, Note 3 ). Thus, it is extremely critical for this type of research that any display changes occur at a time when the stimulus movement associated with the change is not perceived. No study has yet been done which shows how late in the saccade, or how early in the fixation, these changes can be made without the simple existence of movement on the CRTs having an effect on reading, and no study has employed an appropriate control condition for such an influence. Of course, the claim that peripheral visual information is being acquired and used to facilitate later foveal perceptual processing is based on the assumption that some or all of the observed effects of display changes in the relevant studies have arisen from the second influence, nonidentical stimulus patterns on successive fixations, rather than from either of the others.

All but the studies which have involved reading of continuous text have also used text-inappropriate peripheral visual patterns-words spelled backwards (O'Regan, 1980), other letters substituted for text original letters (McConkie \& Rayner, 1975, 1976b; Rayner, 1975; Underwood \& McConkie, Note 1), or gratings (Rayner \& Bertera, 1979; Rayner, Inhoff, Morrison, Slowiaczek, \& Bertera, 1981; Rayner \& Pollatsek, 1981). Thus, it is possible that in all such studies the changes in reading which were observed resulted from the presence of inappropriate peripheral visual patterns themselves, rather than from the existence of change in the pattern from one fixation to the next.

The two studies in which this was not the case, other than the present one, were by Rayner (1975) and McConkie (Note 4). In the Rayner study, there was one condition (condition W-SL) in which the content of one word location was changed from one word to a second during the saccade which took the eyes to that word. Both words were appropriate in the context, and they had the same initial and final letters and the same general word shape. The present study would seem to have produced a potentially more noticeable change, since the initial letter was changed and in many of the instances the word shape was changed as well. Still, Rayner found an effect of his manipulation, an increase of about $20 \mathrm{msec}$ in the immediately following fixation duration, whereas the present study found no effect. It is possible that the effect in the Rayner study was actually due to the third type of influence, detection of movement in the display associated with the making of the change. Several analyses were conducted to consider this possibility at the time the study was done (Rayner, 1974), and all but one yielded nonsignificant results. However, a reconsideration of the data presented indicates that, while the differences were not large, most were in the direction suggested by the hypothesis that changes were indeed being seen. For instance, when fixations were divided into those which occurred on the letter following the boundary that triggered the display change (and thus had the greatest possibility for the change's occurring after the saccade was completed) vs. fixations further from the boundary (which hence provided greater saccade time after a change was called for), only one of five tests was significant, but four of the five showed longer fixations in the first case than in the second. The average difference between the means of these five comparisons was greater than the 20 -msec difference found for the experimental manipulation in the study. In contrast to this study, in which display changes could be triggered late in the saccade and thus might not be complete until the eyes were actually in fixation, both the present study and a previous one (McConkie, Note 4) made changes only early in the saccade. McConkie (Note 4) caused a single letter to change during each saccade, alternating the contents of a critical location between two words, both of which were contextually appropriate. In the present study, two letters were changed. In both studies, the change occurred about $8 \mathrm{msec}$ after the onset of the saccade, and since it required only $3 \mathrm{msec}$, it was completed long before the end of the saccade, which lasted at least $20 \mathrm{msec}$. Neither of these studies provided any evidence that changing a word from one fixation to the next had any effect on reading unless the reader later reread the word. Thus, it may be that when effects of changing words or letters from one fixation to the next have been observed in the reading of continuous text, these were due to the presence of erroneous or inappropriate peripheral patterns during fixations, or to perceived movement of the text when changes occurred late in saccades or early in fixations, rather than to the mismatch of visual patterns from one fixation to the next.

The present results seem particularly damaging to two proposals that have been made concerning the use of peripheral information. Bouma (1978) suggested that information from the periphery was transmitted to the brain much more slowly than foveal information, and that in a series of fixations during reading the peripherally obtained information from a word and the later foveally obtained information from the same word arrived at appropriate brain centers at about the same time, thus supporting one another and facilitating the perception of that word. Smith (1971) proposed that the region within which words are read was sufficiently large for the same word to be actually read on several fixations, thus facilitating processing and providing redundancy which would inhibit misreadings. It seems clear that neither of these proposals describes perception of the words studied in the present experiment. Rather, the 
evidence indicates that the words were read with information obtained during only one fixation.

Even if peripheral information is not being used to facilitate later foveal perception, this is not to say that peripheral information is not useful during reading. Other studies indicate that sometimes words not directly fixated are still being read (Kliegl, Olson, \& Davidson, in press; Hogaboam, Note 5) and that lengths of words in the periphery, quite apart from their other characteristics, can influence where the eyes are sent on a saccade (O'Regan, 1980). However, these are characteristics of the stimulus that are available peripherally from the present fixation, and do not require integration across fixations. If some type of information is being carried across fixations in reading, its nature is not presently apparent. The carry-over of strictly visual aspects of letters and word shapes does not seem to occur (McConkie \& Zola, 1979), and the present study seems to eliminate the carry-over of specific letters or semantic information. The fact that changing words has no effect eliminates the possibility of semantic priming based on peripheral patterns (Inhoff \& Rayner, 1980). In summary, then, these results argue that reading is based on available retinal information rather than on patterns perceived during prior fixations. Whether good readers are more adept at using available peripheral information (Fisher, 1976; Patberg \& Yonas, 1978) or not (Underwood, Note 6) is still a matter requiring investigation.

The results of this study also argue that the region within which visual information is used for word identification during a fixation is defined in terms of word units, not a specific number of letters to left and right of the fixation (McConkie, in press). While there has been prior evidence that this is so to the left of the fixation point (Rayner, Well, \& Pollatsek, 1980), the same is not true for the region to the right (Underwood \& McConkie, Note 1). For instance, these last investigators found that when letters beyond the third to the right of the fixation point were replaced by other letters, the disruptive effect was just as great when this manipulation did not cause a change in the fixated word as when it did. The same was true when all letters beyond the fifth to the right were replaced. Thus, there was no evidence that errors were not being perceived when they lay outside the fixated word, or that this occurred less frequently or had less of an effect. Combining these results with the results of the present study raises an interesting question. Is it possible that during a fixation the reader responds to orthographic irregularities in a word that is not identified on the fixation, and yet, at the same time, does not use information perceived from such a word when it is brought into the fovea on the next fixation? Since the present data are insufficient to answer this question, it must remain a topic for future investigation. If the answer is positive, this will be strong evidence that orthographic structure is perceived directly in reading, rather than becoming important only in lexical access (Underwood \& McConkie, Note 1).

Finally, the results from the present study bear directly on the issue of how best to derive a measure of processing time in reading from eye-movement data. One basic question has been whether perception during a fixation should be considered to be in letter or letter-group units (McConkie, Hogaboam, Wolverton, Zola, \& Lucas, 1979) or word units (Just \& Carpenter, 1980; Hogaboam \& McConkie, Note 7). The present results clearly favor the latter and are in harmony with Just and Carpenter's "eyemind assumption," although other evidence indicates that words other than the word fixated are at times read during a fixation (Kliegl, Olson, \& Davidson, 1982; Hogaboam \& McConkie, Note 7). Apparently, at least when a person is reading carefully, five-letter words which are relatively unconstrained are read only when directly fixated.

\section{REFERENCE NOTES}

1. Underwood, N. R., \& McConkie, G. W. The effect of encountering errors at different retinal locations during reading. Unpublished manuscript, Center for the Study of Reading, University of Illinois, 1982.

2. Zola, D. The effect of redundancy on the perception of words in reading (Tech. Rep. 216). Urbana: Center for the Study of Reading, University of Illinois, 1981.

3. Wolverton, G. S. The acquisition of visual information during fixations and saccades in reading. Paper presented at the annual meeting of the American Educational Research Association, San Francisco, April 1979.

4. McConkie, G. W. Where do we read? Paper presented at the annual meeting of the Psychonomic Society, San Antonio, Tex., November 1978.

5. Hogaboam, T. W. Time on text: The use of eye movement records in assigning processing time to text. Paper presented at the annual meeting of the American Educational Research Association, San Francisco, April 1979.

6. Underwood, N. R. The span of letter recognition of good and poor readers (Tech. Rep. 251). Urbana: Center for the Study of Reading, University of Illinois, 1982.

7. Hogaboam, T. W., \& McConkie, G. W. The rocky road from eye fixations to comprehension (Tech. Rep. 207). Urbana: Center for the Study of Reading, University of Illinois, 1981.

\section{REFERENCES}

BoumA, H. Visual search and reading: Eye movements and functional visual field: A tutorial review. In J. Requin (Ed.), Attention and performance VII. Hillsdale, N.J: Erlbaum, 1978.

Fisher, D. F. Spatial factors in reading and search: The case for space. In R. A. Monty \& J. W. Senders (Eds.), Eye movements and psychological processes. Hillsdale, N.J: Erlbaum, 1976.

Haber, R. N. Visual perception. Annual Review of Psychology, $1978,29,31-59$.

Inhoff, A. W., \& RAYner, K. Parafoveal word perception: A case against semantic preprocessing. Perception \& Psychophysics, $1980,27,457-464$.

Just, M. A., \& Carpenter, P. A. A theory of reading: From eye 
fixations to comprehension. Psychological Review, 1980, 87, 329-354.

Kliegl, R., Olson, R. K., \& Davidson, B. J. Regression analysis as a tool for studying reading processes: Comment on Just and Carpenter's eye fixation theory. Memory \& Cognition, $1982,10,287-296$.

Kliegl, R., Olson, R. K., \& Davidson, B. J. On problems of unconfounding perceptual and language processes. In $\mathrm{K}$. Rayner (Ed.), Eye movements in reading: Perceptual and language processes. New York: Academic Press, in press.

McClelland, J. L., \& O'Regan, J. K. Expectations increase the benefit derived from parafoveal visual information in reading words aloud. Journal of Experimental Psychology: Human Perception and Performance, 1981, 7, 634-644.

McConxie, G. W. On the role and control of eye movements in reading. In P. A. Kolers, M. E. Wrolstad, \& H. Bouma (Eds.), Processing of visible language. New York: Plenum Press, 1979.

McConkie, G. W. Eye movements and perception during reading. In K. Rayner (Ed.), Eye movements in reading: Perceptual and language processes. New York: Academic Press, in press.

McConkie, G. W., Hogaboam, T. W., Wolventon, G. S., Zola, D., \& Lucas, P. A. Toward the use of eye movements in the study of language processing. Discourse Processes, 1979, 2, 157-177.

McConkie, G. W., \& RAYNer, K. The span of the effective stimulus during a fixation in reading. Perception \& Psychophysics, 1975, 17, 578-586.

McConkie, G. W., \& RAyner, K. Identifying the span of the effective stimulus in reading: Literature review and theories of reading. In H. Singer \& R. B. Ruddell (Eds.), Theoretical models and processes of reading. Newark, Del: International Reading Association, 1976. (a)

McConkis, G. W., \& Rayngr, K. Asymmetry of the perceptual span in reading. Bulletin of the Psychonomic Society, 1976, 8, 365-368. (b)

McConkie, G. W., \& Zola, D. Is visual information integrated across successive fixations in reading? Perception \& Psychophysics, .1979, 25, 221-224.

O'Regan, $K$. The control of saccade size and fixation duration in reading: The limits of linguistic control. Perception \& Psychophysics, 1980, 28, 112-117.

O'REGAN, K. The "convenient viewing position" hypothesis. In D. F. Fisher, R. A. Monty, \& J. W. Senders (Eds.), Eye movements: Cognition and visual perception. Hillsdale, N.J: Erlbaum, 1981.

PaAP, K. R., \& Newsome, S. L. Parafoveal information is not sufficient to produce semantic or visual priming. Perception \& Psychophysics, 1981, 29, 457-466.

Patberg, J. P., \& Yonas, A. The effects of the reader's skill and the difficulty of the text on the perceptual span in reading. Journal of Experimental Psychology: Human Perception and Performance, 1978, 4, 545-552.

RAYNER, K. The perceptual span and peripheral cues in reading. Unpublished dissertation, Cornell University, 1974.

RAYNER, $K$. The perceptual span and peripheral cues in reading. Cognitive Psychology, 1975, 7, 65-81,

RAYNER, K. Foveal and parafoveal cues in reading. In J. Requin (Ed.), Attention and performance VII. Hillsdale, N.J: Erlbaum, 1978.

RAYNER, K. Eye guidance in reading: Fixation locations within words. Perception, 1979, 8, 21-30. (a)

RAYNER, $K$. Eye movements in reading: Eye guidance and integration. In P. A. Kolers, M. E. Wrolstad, \& H. Bouma (Eds.), Processing of visible language. New York: Plenum Press, 1979. (b)

RAYNer, K., \& Bertera, J. H. Reading without a fovea. Science, $1979,206,468-469$.

Rayner, K., Inhoff, A. W., Morrison, R. E., SlowiaczeK, M. L., \& Bertera, J. H. Masking of foveal and parafoveal vision during eye fixations in reading. Journal of Experimental Psychology: Human Perception and Performance, 1981, 7, 167-179.

Rayner, K., McConkie, G. W., \& Ehrlich, S. Eye movements and integrating information across fixations. Journal of Experimental Psychology: Human Perception and Performance, 1978, 4, 529-544.

RAyner, K., McConkie, G. W., \& ZolA, D. Integrating information across eye movements. Cognitive Psychology, 1980, $12,206-226$.

Raynen, K., \& Pollatsek, A. Eye movement control during reading: Evidence for direct control. Quarterly Journal of Experimental Psychology, 1981, 33, 351-373.

Rayner, K., Well, A. D., \& Pollatse K, A. Asymmetry of the effective visual field in reading. Perception \& Psychophysics, 1980,27, 537-544.

SmITH, F. Understanding reading. New York: Holt, Rinehart \& Winston, 1971.

\section{APPENDIX}

1. As Kevin approached his grandfather's bungalo down the long country lane, he was taken aback by its /weedy/weepy/seedy/seepy/ appearance and its need for a coat of paint.

2. Ruth's great aunt is definitely the most /mushy/musty/ gushy/gusty/ person she has ever met.

3. Dr. Koppof was able to demonstrate that the /blare/ blame/flare/flame/ which had been so disconcerting to the natives of the region originated from a neighboring tribe.

4. With considerable hesitation, Phil asked Sue to /trade/ trace/grade/grace/ his table, not knowing what the outcome might be.

5. English teachers typically believe that formal writing has the ability to clean out the /musty/musky/dusty/dusky/ reaches of the mind and that it contributes to clear thinking.

6 . The second grader was doing very well in the spelling bee until he was given the word '/couch/cough/touch/ tough/', which he missed by a single letter.

7. Mr. Gilmore has written a book in which he classifies /peaks/pears/beaks/bears/ from around the world. However, it will never be a best seller.

8. They have interesting /meals/meats/seals/seats/ at the Emporium. You really should make a visit there the next time you are in the city.

9. While the old herder shivered in front of his potbellied stove, he was led to contemplate the results of his actions. While having his /goats/goals/coats/coals/ high seemed like a good idea at the time, he now realized the disadvantages.

10. Mr. Blackwell was, in order, an industrialist, a runner, a collector, and a hypochondriac. The many /pills/ piles/mills/miles/ he had accumulated over the years were often the topic of conversation among his friends.

11. The Recreation Housing Committee reported that five /teams/tears/beams/bears/ were recently discovered that we previously did not know about. Boyd has been assigned to seek more information and to report back to the Committee.

12. The high point of the Great Zaslow's act is when he /leads/leaps/heads/heaps/ all twenty tigers toward the gate of the cage at once.

13. It has been whispered that deaf Talu /beats/bears/ heats/hears/ his chickens in the large bamboo cage. 
14. In this particular form of treatment, the physician /seats/seals/heats/heals/ the injured bone directly in the socket.

15. Rosslyn decided that her husband's music and his /feats/fears/beats/bears/ were no longer tolerable and it was finally time for her to leave.

16. The children rang the school bell as the old teacher shopped at the fruit market next door. "Although 1 love the /dears/deals/pears/peals/," she said mournfully, "I can't take any more of them for a few days."

17. Everyone knows about the /raids/rails/maids/mails/ in my country, but the government is unable to do anything about them.

18. It has been said that a highly trained dog /heels/ heeds/feels/feeds/ well only at the call of its master.

19. The old peddler had so many /warts/wares/carts/ cares/ that it was hard for him to exert enough energy to make his way along the streets of the city.
20. After a careful examination of the Frenchman's /works/words/corks/cords/ the judges declared him to be the winner.

21. The officer inspected the /belts/bells/welts/wells/ before having his supper.

22. After hours of searching for them, the old /deans/ dears/beans/bears/ were found in the park.

23. As the moon slid behind the clouds, the /yards/ yarns/bards/barns/ had a strange effect on him.

24. The anthropologist, Dr. Barter, claimed that, unlike the compassionate and helpful Samoans, an Eskimo fisherman never /baits/bails/waits/wails/ for anyone, even his closest friends.

25. Yesterday afternoon Mr. Johns showed his /warts/ wares/harts/hares/to his friends.

(Manuscript received February 10, 1982; accepted for publication June 11,1982 .) 